\title{
Hypertension in pregnancy
}

\author{
E Malcolm Symonds
}

The classification of high blood pressure in pregnancy is important for predicting outcome and determining the best method of treatment. The most widely used classification is the one proposed by the American College of Obstetrics and Gynecology (ACOG) which divides hypertension arising during pregnancy from pregnancy complicating hypertensive states. ${ }^{1}$ This classification has been further simplified by the International Society for the Study of Hypertension in Pregnancy, ${ }^{2}$ but the important feature in both classifications is the differentiation between the occurrence of hypertension alone and hypertension plus proteinuria or pre-eclampsia. Both maternal and perinatal mortality rates are significantly increased in pre-eclampsia but not with gestational hypertension. The implication of other forms of hypertension present during pregnancy varies according to the type of underlying pathology.

Gestational hypertension is the most common form of hypertension complicating pregnancy, and pre-eclampsia and eclampsia are the most common cause of perinatal or maternal death. In the last triennial report on Confidential Enquiries into Maternal Deaths in the United Kingdom (1988-1990), ${ }^{3}$ hypertensive disorders remained the highest single cause of maternal death in England and Wales, with a rate of 8.6 deaths per million pregnancies, compared with 8.0 deaths per million from pulmonary embolism. Deaths as a result of anaesthesia dropped from 8.7 in $1979-81$ to 1.0 per million in 1988-90; the corresponding figures for hypertensive disorders were $14 \cdot 2$ to $8 \cdot 6$ per million.

A breakdown of immediate causes of death shows that intracerebral haemorrhage was the most common, followed by adult respiratory distress syndrome. In the last triennium only three deaths were considered to be related to the HELLP syndrome. This syndrome represents a manifestation of severe pre-eclampsia and includes the triad of haemolysis $(\mathrm{H})$ raised liver enzymes (LE), and a low platelet count (LP). The thrombocytopenia is often severe, unlike the milder forms of pre-eclampsia where it occurs in less than $20 \%$ of cases. On examination of the effect of hypertensive disease in pregnancy on the fetus in utero, it is clear that the onset of late hypertension alone has much less effect than hypertension and proteinuria on perinatal mortality. In a review of 13980 primigravidae in Aberdeen between 1958-72,
MacGillivray demonstrated that the perinatal mortality rate in normotensive primigravidae was 20.7 per 1000 births; in hypertension alone it was 18.9 per 1000 births; and in hypertension with proteinuria the figure was $55 \cdot 0$ per 1000 births. ${ }^{4}$ In other words if a woman develops hypertension alone during pregnancy she tends to do rather better than if she remains normotensive. If the mother develops hypertension and proteinuria during pregnancy the outcome is considerably worse than either of the other groups. The problem is that such assessments can be made only in retrospect and, therefore, it is impossible to predict the likelihood of progression to preeclampsia in a woman who initially develops hypertension alone.

\section{The pathogenesis of pre-eclampsia}

In normal pregnancy cardiac output increases by $30-40 \%$ within the first 14 weeks and remains raised throughout pregnancy. This increase is largely related to an increase in stroke volume. At the same time plasma volume expands by $40 \%$ but this expansion occurs progressively until about 36 weeks' gestation. Blood pressure also decreases to reach a nadir during the second trimester and this is inconsistent with the changes in cardiac output and plasma volume. The only explanation for this anomalous state in normal pregnancy is that there must be a reduction in total peripheral resistance. However, not all vascular beds exhibit a reduction in resistance. Studies on forearm blood flow, for example, ${ }^{5}$ have demonstrated a reduction in normal pregnancy and an increase in hypertensive diseases in pregnancy. The predominant changes in resistance vessels seem to occur in the uteroplacental circulation or in the kidney. Normal pregnancy is also associated with pronounced veno-dilatation, ${ }^{6}$ but there is relative venoconstriction where the woman has developed pre-eclampsia or gestational hypertension alone.

The end manifestation of all these vascular changes is to produce widespread vascular and endothelial damage in multiple organ systems, but the arguments about pathogenesis revolve around two questions.

Firstly, does the hypertension develop as a secondary manifestation of vascular damage caused by some initiating factors? Secondly, does the vasoconstriction occur because of a 
vasoconstrictive factor or because of the loss of normal vasodilatation?

The search for an initiating factor has been singularly unforthcoming and it seems likely that pre-eclampsia represents a form of maladaptation rather than a disease process initiated by a single substance. The question as to whether the focal vasoconstriction, which is a feature of pre-eclampsia and eclampsia, results from an increase in vasoconstrictor activity or a decrease in vasodilator activity, remains unanswered. Although normal pregnancy represents a state of vasodilatation and reduced vascular resistance, the change in angiotensin II (AII) receptor activity and the increased concentrations of thromboxane $\mathrm{A}_{2}$, which will be discussed later in this review, favour the dominance of a vasoconstrictor effect in pre-eclampsia.

\section{Predisposing factors}

Gestational hypertension and pre-eclampsia occur most frequently in primigravid women and there are numerous studies to confirm this observation. The incidence of pre-eclampsia in women who have had a first pregnancy complicated by spontaneous abortion was found to be reduced ${ }^{7}$ but more recent studies have suggested that the incidence of pre-eclampsia in a second pregnancy after a spontaneous or induced abortion is still much greater than the usual incidence in second pregnancies. ${ }^{8}$ These observations are relevant to the possible immune response to fetal antigens. Parous women with new husbands are at increased risk of pre-eclampsia. ${ }^{9}$

GENETIC AND FAMILIAL FACTORS

There has always been a belief that a genetic trait might underlie the occurrence of preeclampsia. It has, however, been too difficult to measure any such claim against the effect of parity and environmental factors. In a remarkable study extending over a period of 50 years Chesley studied a cohort of women and their families over successive generations. ${ }^{10}$ The incidence of pre-eclampsia and eclampsia in 147 sisters, 248 daughters, 74 granddaughters and 131 daughters in law showed an observed incidence that fitted closely with a single gene condition and with a putative gene frequency of $0 \cdot 25$. The search for a specific gene suggests a gene on chromosomes $1,3,9$, and $18,{ }^{11}$ and recently studies have suggested that a molecular variant of angiotensinogen might be implicated in the development of preeclampsia. ${ }^{12}$ Arngrimsson and co-workers also identified a genetic factor in Icelandic women. ${ }^{13}$ Nevertheless, it is still difficult to formulate an hypothesis that accounts for the development of hypertension in later pregnancies, even though the condition largely occurs in primigravid women.

MATERNAL AGE

The analysis of the effect of maternal age reported in the Confidential Enquiries into
Maternal Deaths in the United Kingdom ${ }^{3}$ shows that the lowest incidence of maternal mortality from the effect of hypertensive disease in pregnancy occurred in women aged 25-29 years and the highest incidence occurred in women over the age of 40 .

\section{MULTIPLE PREGNANCY}

Several studies have shown that twinning is associated with an increased incidence of pre-eclampsia. ${ }^{7}$ There is, however, some dispute as to whether zygocity exerts any effect on incidence. Campbell was unable to demonstrate any differences in the incidence of pre-eclampsia in women who had monozygotic or dizygotic twins, ${ }^{14}$ but Stevenson et al suggested that pre-eclampsia was common with dizygotic twins and that women with different sex twins had a higher incidence of pre-eclampsia. ${ }^{15}$

DIABETES, HYDATIDIFORM MOLE, AND HYDROPS FETALIS

There seems to be a higher incidence of pre-eclampsia in women who have diabetes mellitus, although it has been suggested that this is largely associated with poorly controlled diabetes. The United Kingdom survey of diabetic pregnancies has suggested a figure of $12 \%{ }^{16}$ Diabetes is complicated by hyperplacentosis where hypertrophy of the placenta and, in particular, hyperplasia of cytotrophoblastic tissue remains a feature associated with pre-eclampsia. This condition is also found in hydatidiform mole and hydrops fetalis, both of which are also associated with a high incidence of pre-eclampsia.

\section{CIGARETTE SMOKING}

Several studies have now demonstrated that the incidence of pre-eclampsia in primigravidae falls from $5 \cdot 2 \%$ in smokers to $2 \cdot 4 \%$ in non-smokers. ${ }^{17}$ If the woman does acquire pre-eclampsia and is a smoker, then the chances of her having fetal compromise or fetal death are substantially increased.

\section{Vasoactive substances and the regulation} of blood pressure

There are a large number of vasoactive substances produced within the placental bed which have always been a source of interest when studying the pathogenesis of pre-eclampsia. Some systems produce potent vasoconstrictors and others produce vasodilators.

\section{THE RENIN-ANGIOTENSIN SYSTEM}

Renin is a proteolytic enzyme which is produced in its active form by cleavage of a 436 amino acid prosignal from a prorenin precursor. Although the enzyme was first identified in the kidney, it has since been shown to be produced in the human chorion, ${ }^{18}$ myometrium, brain and smooth muscle. Renin 
acts on angiotensinogen to cleave an inert decapeptide, angiotensin I, which is then broken down to angiotensin II (AII) which, among other things, is a potent vasoconstrictor. The system is hyperactive during normal pregnancy, but it is of particular interest in pregnancy because the normal pregnant woman becomes notably insensitive to infused AII, whereas the women who are destined to develop pre-eclampsia and those who have acquired the disease exhibit an increased sensitivity to AII, reaching levels of response that are similar to those of non-pregnant women.

Using platelets as a model of smooth muscle function, it has been possible to show that binding site density for AII falls during pregnancy in parallel with the fall in AII sensitivity, and those women who develop pre-eclampsia also show an increase in platelet AII binding sites. ${ }^{19}$ Furthermore, platelet AII binding site density seems to be a better predictor of pre-eclampsia than the angiotensin sensitivity test. The reduction in AII sensitivity may be a direct result of inhibition of platelet AII receptor activity.

\section{THE EICOSANOID SYSTEM}

There have been numerous studies on this system and on the balance between the vasodilator effects of prostacyclin and the vasoconstrictor effect of thromboxane AII. Studies on uterine venous blood in preeclamptic patients and normal controls showed increased concentrations of thromboxane AII and decreased concentrations of 6-keto-PGF $1 \alpha$ in pre-eclamptic women with a ratio of 5.6 compared with $2 \cdot 0$ in normotensive women (Mortensson L, et al. Abstract presented at Annual Meeting of Society of Gynaecologists, 1984). PGI $_{2}$ has an antiaggregatory effect on platelets; thromboxane AII causes platelet aggregation which probably results in the release of serotonin from the platelets, ${ }^{20}$ thus resulting in the increased concentrations of circulating serotonin which can be found in pre-eclamptic women. ${ }^{21}$

\section{LIPID PEROXIDATION AND OXYGEN RADICALS}

In a recent review of lipid peroxides and oxygen free radicals in normal and hypertensive pregnancies, Walsh concluded that the production of antioxidants in normal pregnancy limits the damaging effects of lipid peroxides which are normally increased in pregnancy. ${ }^{22}$ In women who developed preeclampsia net antioxidant activity is decreased and hence cell damage may result. Glutathione peroxidase is a primary antioxidant and limits the production of lipid peroxides; the activity of this enzyme is significantly below normal in the placental tissue of pre-eclamptic women.

\section{ENDOTHELINS}

A great deal of research activity is currently taking place in the field of endothelial damage and in endothelially derived hormones such as endothelin. There are four isoforms of endothelin, each encoded by a different gene. They are potent vasoconstrictors with secondary effects on the renin-angiotensin system. So far, most studies have failed to show any differences in the plasma measurements between normal and pre-eclamptic women.

\section{VASODILATORS}

Nitric oxide (NO) or endothelium derived relaxing factor (EDRF) is a potent vasodilator. Inhibition of nitric oxide synthetase increases blood pressure in non-pregnant women. In recent studies in pregnancy where NO synthesis was assessed indirectly by measurement of urinary nitrate or nitrite secretion, the findings showed that nitrate or nitrite excretion is reduced in women with pre-eclampsia. ${ }^{24}$ These changes may be related to impaired renal production of nitric oxide production in pre-eclamptic women.

The kallikrein-kinin system is also a candidate for vasodilation in normal pregnancy; its absence may result in vasoconstriction. Kinin is formed by the action of kallikrein on a substrate of kininogen. There are differences between the kallikrein-kinin system in plasma and in tissues. The kidneys produce tissue kallikrein and urinary kallikrein is purely renal in origin.

In normal pregnancy maximum concentrations of active urinary kallikrein occur towards the end of the first trimester, with levels falling in advancing pregnancy. ${ }^{24}$ Several groups 2526 have shown that kallikrein concentrations are significantly lower in hypertensive pregnant women, compared with normal pregnancy. Furthermore, the same differences occur in inactive urinary kallikrein and these differences can be seen in the first trimester. ${ }^{24}$ Subsequent reports have shown that the inactive urinary kallikrein to creatinine ratio, measured at 14 to 20 weeks' gestation, can be used to predict the development of pre-eclampsia (Kyle P M, et al. Abstract presented at International Society for Study of Hypertension in Pregnancy, Buenos Aires, 1992).

In summary, the mechanism of hypertension developing during pregnancy seems to be related to the balance between vasodilator and vasoconstrictor substances produced during pregnancy, but the situation is complex and multifactorial.

\section{CHANGES IN THE COAGULATION SYSTEM}

Severe pre-eclampsia is associated with abnormalities of the coagulation system and observations related to this subject date back to the last century. There has always been a debate about whether these changes involving disseminated intravascular coagulation are primary or secondary in nature. The bulk of evidence now available very much suggests that the changes are likely to be secondary and not causative.

Platelet function and numbers are both 
altered during normal and pre-eclamptic pregnancies. There is no doubt that the platelet count is reduced in women with severe pre-eclampsia, but severe changes occur in only about $15 \%$ of women with severe disease. $^{27}$ Platelet lifespan is reduced in women with established pre-eclampsia. ${ }^{28}$ Factor VIII clotting activity is increased above normal for the accepted range in pregnancy and factor VIII consumption is increased in both pre-eclampsia and intrauterine growth retardation. ${ }^{29}$

Antithrombin III activity ${ }^{30}$ remains constant in normal pregnancy but shows a significant decline in pre-eclampsia. ${ }^{32}$ This is directly related to the severity of the disease process and may predate the onset of clinical disease.

Fibrin metabolism is significantly altered in normal pregnancy with a rise in plasma fibrinogen. There is increased generation of fibrin during normal pregnancy but widespread deposition of fibrin does not occur. In pre-eclampsia, fibrinolytic activity seems to be reduced whereas fibrin generation increases. ${ }^{31}$ Deposits of fibrin or fibrin-like material are widespread and fibrin degradation products are increased in women with severe preeclampsia. ${ }^{32}$

Finally, the deposition of fibrin is often associated with fibronectin and laminin ${ }^{33}$ and it is not surprising that plasma concentrations of fibronectin and laminin are increased in women with pre-eclampsia.

\section{PLACENTATION}

The changes that occur in early placentation in normal pregnancy have been well documented. During the first trimester, extravillous cytotrophoblast moves from the tip of anchoring villi to the spiral arteries in the placental bed and migrates down the intima of the vessels destroying the normal musculo-elastic tissue and creating flaccid sinusoidal channels. However, Brosens and his colleagues demonstrated that the second wave of invasion failed in women who developed pre-eclampsia and the conversion of spiral arteries to a flaccid structure did not occur. ${ }^{34}$ Thus from the early second trimester, the impairment of the development of normal uteroplacental blood flow and consequent fetal growth impairment seems to be inevitable. There has been much speculation as to why the invasion is defective and whether it has an immunological basis, and also whether it plays a critical part in the development of hypertensive disease in pregnancy.

\section{The prevention of pre-eclampsia}

The concept that it may be possible to prevent pre-eclampsia presents the most favourable option in any therapeutic proposal and a great deal of effort has therefore been directed at developing methods for selecting individuals at high risk of pre-eclampsia and giving them prophylaxis. Numerous techniques for the prediction of pre-eclampsia have been explored and these have recently been reviewed. ${ }^{35}$ The methods include mid-trimester blood pressure measurements, the detection of microalbuminuria, cold pressor tests, isometric exercise tests, roll-over tests, angiotensin infusion tests, and the measurement of platelet AII receptors. Biochemical markers such as uric acid, calcium excretion, and the excretion of prostacyclin metabolites, urinary kallikrein measurements, and certain coagulation factors, particularly in relation to fibronectin and antithrombin III concentrations, have all been explored. It is reasonable to conclude that, at this stage, none of these tests has been ideal. However, the two tests with the highest predictive accuracy at present are angiotensin sensitivity tests and mid-trimester platelet AII receptor measurements.

\section{LOW DOSE ASPIRIN}

Aspirin, or acetylsalicylic acid, acts as an inhibitor of cyclo-oxygenase activity and of platelet aggregation when used in low doses. It has been extensively studied in relatively high doses taken during pregnancy but no real problems in terms of ductus closure have been demonstrated in the fetus. Ylikorkala and his group have shown in studies on umbilical arteries that a single dose of $500 \mathrm{mg}$ of aspirin ingested by the mother significantly reduced prostacyclin and thromboxane synthesis, whereas $100 \mathrm{mg}$ aspirin did not affect prostacyclin synthesis. ${ }^{36}$ The first clinical trial of prophylaxis with low dose aspirin in pregnancy induced hypertension was reported by Beaufils et $a l^{37}$ and the following year Wallenburg ${ }^{38}$ and colleagues produced the results of a randomised, placebo-controlled, double blind study using $60 \mathrm{mg}$ of aspirin daily and selecting patients by using the angiotensin sensitivity test at 28 weeks' gestation. The study was performed on 24 women. Two of the 21 women developed mild hypertension, whereas 12 of the placebo group developed hypertension of varying degrees of severity.

Since that study, several trials have started. The largest of the multicentre trials has been the Collaborative Low-dose Aspirin Study in Pregnancy (CLASP) trial $^{39}$ which admitted only those women in whom there was significant doubt as to whether they would benefit from aspirin. The results generally indicated only very marginal value in preventing preeclampsia and, therefore, the implication is that low dose aspirin carries very little benefit. It must, however, be remembered that the Dutch study was subject to meticulous selection procedures and it is likely that there is a selected group within this large cohort of patients that would benefit from aspirin. There is a case for a study on primigravid women selected as high risk and subjecting them to a randomised, double blind controlled trial.

\section{The management of pre-eclampsia}

Between 1-15\% of British women develop hypertension during pregnancy and about $10 \%$ of them develop proteinuria as well. Most 
definitions state that hypertension in pregnancy is defined as 'the occurrence of a blood pressure of $140 / 90 \mathrm{~mm} \mathrm{Hg}$ or more on two or more occasions at least six hours apart in a woman shown to be normotensive before the onset of pregnancy'. Clinically important proteinuria is defined as $300 \mathrm{mg} / \mathrm{l}$ in a 24 hour specimen.

The management of mild gestational hypertension has been based on the premise that mild hypertension in likely to progress to preeclampsia and eclampsia and, therefore, it was advantageous to keep to women resting in hospital. However, it is now well established that those women who develop gestational hypertension alone do not exhibit increased maternal or perinatal loss and therefore home management with day case attendances at pregnancy assessment units is becoming the favoured option. Women can be taught to assess their own blood pressure and urine and to report to the centre should abnormal signs develop. The assessment of fetal growth and welfare is essential.

THE ROLE OF DRUG TREATMENT

As mild or moderate hypertension without proteinuria have little adverse effect on fetal or maternal welfare, the justification for controlling blood pressure has to be based on the protection of the mother's cerebrovascular circulation and in preventing progression to proteinuric hypertensive disease. Such objectives must be achieved without detriment to the fetus as a result of side effects that the drug may have on the fetus or neonate. Thus antihypertensive treatment is indicated where hypertension persists and where it is desirable to prolong gestation. Many obstetricians take the view that if it is possible to keep the infant alive in the special care baby unit (SCBU) with a good chance of survival then early delivery is preferable. However, if the fetus can be safely kept in utero and requires minimal time in a SCBU, this must be the preferred option.

\section{CENTRALLY ACTING ANTIHYPERTENSIVE AGENTS}

The drugs most commonly used in clinical practice in mild hypertension are centrally acting antihypertensive agents such as $\alpha$ methyldopa. This drug has been used extensively. It often has unpleasant side effects for the mother, but apart from occasional hypoglycaemia and mild hypertension, it has singularly little adverse effect on the neonate.

\section{SYMPATHOLYTIC AGENTS}

A wide range of $\beta$ blockers and some combined $\alpha$ and $\beta$ sympathetic blocking agents have been used in pregnancy, but the most widely used compounds in the United Kingdom are labetalol and atenolol. Other compounds used include sotalol, metoprolol, acebutolol and oxprenalol. All of these compounds may cause neonatal bradycardia, hypotension, and hypoglycaemia when used in high doses and their various actions have been described in a comprehensive review by Broughton Pipkin. ${ }^{40}$

\section{CALCIUM CHANNEL INHIBITORS}

These compounds act by preventing the ingress of calcium to the smooth muscle cell. Although they have not been widely used in pregnancy hypertension, drugs such as nifedipine have been shown to be very effective in controlling blood pressure in severely hypertensive women, ${ }^{41}$ but their use has been limited because of theoretical concerns about teratogenic effects. Any teratogenic effects are of limited relevance as treatment for pre-eclampsia is required in the second and third trimester of pregnancy. However, there are no controlled studies of the use of these compounds in pregnancy and caution should still be exercised in their use. Concurrent use of calcium antagonists and magnesium sulphate should be avoided.

\section{ANGIOTENSIN CONVERTING ENZYME \\ INHIBITORS}

Captopril administered to pregnant sheep and rabbits ${ }^{42}$ severely compromises fetal and neonatal survival. In a study of 12 human pregnancies oligohydramnios and neonatal anuria were noted in four cases and in three cases there were perinatal deaths. ${ }^{43}$ This drug should be avoided where possible in pregnancy.

Mild to moderate hypertension should be managed by careful observation of both mother and fetus and by timely intervention when a reasonable gestation age is achieved. This objective can sometimes be achieved by the use of antihypertensive drugs.

\section{Severe pre-eclampsia and eclampsia}

The principal objectives of management in this condition are to control the fits and blood pressure and to deliver a live infant. It is rarely possible to prolong such pregnancy more than a few days without the risk of developing the HELLP syndrome in the mother, with subsequent fetal or neonatal death.

Severe pre-eclampsia and eclampsia constitute an obstetric emergency and it is essential to prevent convulsions by early intervention if there are signs of hyperreflexia and symptoms of frontal headache and epigastric pain. Convulsions can be controlled by slow intravenous infusion of $20 \mathrm{mg}$ of diazepam, but urgent transfer to hospital is essential where intensive care facilities are available.

Hydralazine is still the drug of choice for acute control of blood pressure. Initial intravenous administration with a continuous infusion with subsequent intramuscular injections should stabilise the blood pressure at $90 \mathrm{~mm} \mathrm{Hg}$ diastolic pressure so that delivery can be planned.

Probably the most important change in management regimens has been the introduction of careful regulation of blood volume and the monitoring of pulmonary capillary wedge 
pressures. The expansion of blood volume should be undertaken with monitoring of central venous pressure or by monitoring capillary wedge pressure.

1 Hughes EC. Obstetric-gynecologic terminology. Philadelphia: Davis, 1972.

2 Davey DA, MacGillivray I. The classification and definition of the hypertensive disorders of pregnancy. Clin Exp Hypertens 1986; B5: 97-133.

3 Report on Confidential Enquiries into Maternal Deaths in the United Kingdom. 1988-1990. London: HMSO, 1994, 22-6.

4 MacGillivray I. Pre-eclampsia. In: The hypertensive disease of pregnancy. London: WB Saunders, 1983:181-2.

5 Macpherson MBA. A study of vascular adaptation in human pregnancy. Thesis. University of Nottingham, 1988.

6 Stainer K, Pickles C, Cowley AJ. The effects of posture on abnormalities of forearm venous tone in women with pregnancy induced hypertension. Clin Sci 1987; 73: 267-9.

7 MacGillivray I. Some observations on the incidence of preeclampsia. Fournal of Obstetrics and Gynaecology of the British Commonwealth 1958; 65: 536-9.

8 Campbell DM, MacGillivray I, Carrhill R. Pre-eclampsia in second pregnancy. Br f Obstet Gynaecol 1985; 92: 131-40.

9 Need JA. Pre-eclampsia in pregnancies by different fathers: immunological studies. $B M \mathcal{F} 1975$; i: 548.

10 Chesley LC, Cooper DW. Genetics of hypertension in pregnancy: possible single gene control of pre-eclampsia and eclampsia in the descendants of eclamptic women. $B r \mathcal{F}$ Obstet Gynaecol 1986; 93: 898-908.

11 Hayward C, Livingstone J, Holloway S, Liston WA, Brock DJH. An exclusion map for pre-eclampsia: assuming autosomal recessive inheritance. Am $\mathcal{F}$ Hum Genet 1992; 50: 749-57

12 Ward K, Hata A, Jeunemaitre X, Helin C, Nelson L, Namikawa $C$, et al. A molecular variant of angiotensinogen associated with pre-eclampsia. Nature Genetics 1993; 4: 59-61.

13 Arngrimsson R, Bjornsson S, Giersson RT, Bjornsson H, Walker JJ, Snaedal G. Genetics and familial predisposition to eclampsia and pre-eclampsia in a defined population. Br f Obstet Gynaecol 1990; 97: 762-9.

14 Campbell DM, MacGillivray I, Thompson B. Twin zygosity and pre-eclampsia. Lancet 1977; ii: 97 .

15 Stevenson AC, Davison BCC, Say T, Usutoplus LD, Einen MA, Toppozata HK. Contribution of fetal/maternal incompatibility to aetiology of pre-eclamptic toxaemia. Lancet 1971; ii: 1286.

16 Howy C, Beard RW. Report to the meeting on results of the UK survey of diabetic pregnancies. London: Royal College of Obstetricians and Gynaecologists, 1982

17 Duffus GM, MacGillivray I. The incidence of pre-eclamptic toxaemia in smokers and non-smokers. Lancet 1968; i: 994.

18 Symonds EM, Stanley MA, Skinner SL. Production of renin by in vitro of human chorion and uterine muscle. Nature 1968; 217: 1152-3.

19 Baker PN, Broughton Pipkin F, Symonds EM. A comparative study of platelet angiotensin II binding and
the angiotensin II sensitivity test as predictors of pregnancy induced hypertension. Clin Sci 1992; 83: pregnancy

20 Wallenburg HCS, Rotmans N. Prevention of recurrent idiopathic growth retardation by low-dose aspirin and dipyridamole. Am f Obstet Gynecol 1987; 157: 1230-5.

21 Filshie GM, Maynard PV, Hutter C, Cooper JC, Robinson $G$, Rubin P. Urinary 5-hydroxindole acetic acid concentration in pregnancy induced hypertension. $B M \mathcal{F} 1992$; 304: 1223.

22 Walsh CW. Lipid peroxidation in pregnancy. Hypertension in Pregnancy 1994; 13: 1-32.
23 Brown MA, Tibben E. Nitric oxide in pre-eclampsia. In: Proceedings of the IXth International Congress of the International Society for the Study of Hypertension in Pregnancy, 1994: 298.

24 Campbell SK, Farrer A, Albano JDM, Steel PJ, Millar JGB. The renal kallikrein system in pregnancy. In: Sharp $F$, Symonds EM, eds. Hypertension in pregnancy. New York: Perinatology Press Ithica, 1987: 201-19.

25 Valdes G, Espinoza P, Moore R, Croxatto HR. Urinary kallikrein and plasma renin activity in normal human pregnancy. Hypertension 1981; 6 (supple II): 55 .

26 Kovatz S, Arber I, Korzets Z, Rathaus M, Aderet NB, Bernheim J. Urinary kallikrein in normal pregnancy, preg nancy with hypertension and toxaemia. Nephron 1985: 40 48-51.

27 Pritchard JA, Cunningham FG, Mason RT. Coagulation changes in eclampsia, their frequency and pathogenesis. Am $\mathcal{F}$ Obstet Gynecol 1976; 124: 855-64.

28 Rakoczi I, Tallian F, Bagdany S, Gati I. Platelet life-span in normal pregnancy and pre-eclampsia as determined by a non-radioisotope. Thromb Res 1979; 15:553.

29 Weiner CP. Clotting alterations associated with the pre-eclampsia/eclampsia syndrome. In: Rubin PC, ed. Handbook of hypertension. Vol 10. Hypertension during pregnancy. Amsterdam: Elsevier Science Publishers, 1988: pregnancy.

30 Weiner CP, Brandt J. Plasma antithrombin III activity: an aid in the diagnosis of pre-eclampsia-eclampsia. Am $\mathcal{F}$ Obstet Gynecol 1982; 12: 275.

31 McKillop CA, Howie PW, Forbes CD. Sequential studies in pre-eclampsia using plasma fibrinogin chromatography. Br F Obstet Gynaecol 1977; 84: 909.

32 Howie PW, Prentice CRM, McNicol GP. Coagulation fibrinolysis and platelet function in pre-eclampsia essential hypertension and placental insufficiency. Fournal of Obstetrics and Gynaecology of the British Commonwealth 1971; 78: 992-1003.

33 Stubbs TM, Lazarchick J, Horger EO. Plasma fibronectin levels in pre-eclampsia: a possible biochemical marker for vascular endothelial damage. Am $\mathcal{f}$ Obstet Gynecol 1984; vascular

34 Brosens J, Robertson WB, Dixon HG. The role of spiral arteries in the pathogenesis of pre-eclampsia. Obstet Gynecol Ann 1972; 1: 177-91.

35 Baker PN. The prediction of pre-eclampsia. Current Obstetrics and Gynaecology 1992; 3: 69-74.

36 Ylikorkala O, Mäkilä VM, Kääpä P, Viinikka L. Maternal ingestion of acetylsalicylic acid inhibits fetal and neonatal prostacyclin and thromboxane in humans. $A m \mathcal{F} O b s t e t$ Gynecol 1986; 155: 345-9.

37 Beaufils M, Uzan S, Donsimoni R, Colau JC. Prevention of pre-eclampsia by early antiplatelet therapy. Lancet 1985 ; $\mathrm{i}$ : $840-2$.

38 Wallenburg HCS, Makovitz JW, Dekker GA, Rotmans P. Low dose aspirin prevents pregnancy-induced hypertension and pre-eclampsia in angiotensin-sensitive primiravidae. Lancet 1986; i: $1-3$.

39 CLASP (Collaborative low-dose aspirin study in pregnancy) Collaborative Group, CLASP: a randomised trial of low-dose aspirin for the prevention and treatment of pre-eclampsia among 9364 pregnant women. Lancet 1994: 343: 619-29.

40 Broughton Pipkin F. The effect of maternal drug therapy on the fetus. In: Sharp F, Symonds EM, eds. Hypertension in pregnancy. New York: Perinatology Press, 1986: in pregnanc.

41 Walters BNJ, Redman CWG. Treatment of severe pregnancy-associated hypertension with the calciumpregnancy-associated hypertension with the calciumantagonist $330-6$.

42 Broughton Pipkin F, Symonds EM, Turner SR. The effect of SQ14, 225 (Captopril) upon mother and fetus in the chronically cannulated ewe and in the pregnant rabbit. f Physiol 1982; 323: 415-22.

43 Mochizuki M, Maruo T, Motoyama S. Treatment of hypertension in pregnancy by a combined drug regime including captopril. Clin Exp Hyp 1986; B5: 69-78. 